\title{
Comparison of recent trends in adolescent and adult cigarette smoking behaviour and brand preferences
}

K Michael Cummings, Andrew Hyland, Terry F Pechacek, Mario Orlandi, William R Lynn

\begin{abstract}
Objective-To compare trends in smoking behaviour and use of cigarette brands by adults and adolescents.

Design-Data analysed in this paper come from tobacco use surveys of adults and teenagers conducted in $\mathbf{1 8}$ communities in the United States, as part of the National Cancer Institute's Community Intervention Trial for Smoking Cessation. Data on adult smoking behaviour were obtained from two cross-sectional telephone surveys, one conducted from January to May $1988(n=99348)$, and the second conducted between August 1993 and January $1994(n=79890)$. Data on adolescent smoking behaviour were obtained from two school-based surveys of ninth-grade students (aged 13-16 years), one conducted in autumn $1990(n=7097)$, and the second conducted in autumn 1992 ( $n=$
\end{abstract} 7277).

Outcome measures-Adult cigarette smoking prevalence was estimated as the percentage of adults (18+ years) who were identified either by interview or by proxy as a current smoker. Among adolescents, current smokers were defined as those who reported having smoked on one or more of the 30 days preceding the interview. Cigarette brand use by adults was measured by asking current smokers to report the six digit UPC code on the side of the pack of their current cigarettes. A master list of UPC code numbers was developed so that reported codes could be associated with specific brand names. Among adolescents, cigarette brand use was measured by asking current smokers who reported that they usually buy their own cigarettes: "What brand do you usually buy?"

Results-In ninth-grade students, smoking prevalence rates increased between 1990 and 1992 in 13 of the 18 communities. Among adults, smoking rates declined between 1988 and 1993 in 17 out of 18 communities. Within the same communities, cigarette brand use was found to be much more tightly concentrated in adolescent smokers compared with adults, with teenage smokers more likely to report using the most heavily advertised cigarette brands-Marlboro, Newport, and Camel.
Conclusions-Smoking prevalence rates have increased among teenagers, but have dropped among adults in the same communities. Among adolescents who smoke, and buy their own cigarettes, the three most heavily advertised brandsMarlboro, Camel, and Newport-have a substantially higher market concentration than among adult smokers.

(Tobacco Control 1997;6 (suppl 2):S31-S37)

Keywords: adolescents; brand preferences; cigarette smoking behaviour

Introduction

There has been much debate about the effect of cigarette advertising on smoking behaviour, especially in the young. ${ }^{1-8}$ The cigarette industry's assertion that the sole function of advertising is to promote brand competition has been challenged on the basis that brand switching by smokers does not justify the amount of money spent annually on cigarette marketing. Evidence from two recent studies indicates smokers to be extremely brand loyal, with fewer than $10 \%$ switching brands annually. ${ }^{9} 10$ Furthermore, common sense suggests that for the cigarette industry to retain sales at levels comparable with earlier years, it must replace large numbers of adult smokers who either die or stop smoking each year. As most new smokers are adolescents, it seems logical that at least some cigarette advertising would target this market segment.

Researchers have cited data showing that teenage smokers use the most advertised cigarette brands as evidence to support the assertion that advertising promotes smoking in the young. ${ }^{11-13}$ However, other researchers have rejected such evidence claiming that the brand choices of teenage smokers are more likely attributed to imitating brand choices of adult smokers. ${ }^{8}$ If the latter explanation is correct, one would expect the brand choices of adults and teenagers in the same community to be similar.

This paper uses data collected as part of the National Cancer Institute's Community Intervention Trial for Smoking Cessation (COMMIT) to investigate adult and adolescent cigarette smoking rates and brand preferences in 18 communities in the United States between 1988 and $1993 .{ }^{14}$ The following questions were used to guide analyses of data presented here. 
- Within communities, how comparable are the trends in adult and adolescent smoking prevalence rates?

- Within the same communities, how comparable are the cigarette brand preferences of adult and teenage smokers?

- How have the brand choices of adult and teenage smokers changed over time?

\section{Methods}

COMNIT STLDY

The COMMIT study was a randomised, controlled trial conducted at the community level to test the effectiveness of a multifaceted intervention to help adult smokers achieve and maintain cessation. ${ }^{1+}$ The design and primary outcomes of the COMMIT study have been described elsewhere. ${ }^{15.15}$ Briefly, the study involved 11 matched pairs of communities: 10 paired communities in the United States, and one pair in Canada. Data from the two Canadian communities were excluded. In addition, data from two of the 20 American communities (New Rochelle, New York and Hayward, California) were excluded because of non-participation in the ninth-grade survey by one or more large public schools in each community.

The data come from two cross-sectional telephone surveys of adults conducted in 1988 and 1993, and from two school-based surveys of ninth-grade students (aged 13-16 years) conducted in 1990 and 1992 in 18 of the American COMMIT communities. These communities included Bellingham and Longview/Kelso, Washington; Albany/ Corvallis and Medford/Ashland, Oregon; Vallejo, California; Santa Fe and Las Cruces, New Mexico; Cedar Rapids and Davenport, Iowa; Raleigh and Greensboro, North Carolina; Paterson and Trenton, New Jersey; Lowell and Fitchburg/Leominster, Massachusetts; and Yonkers, Utica, and Binghamton/ Johnson City, New York.

\section{DATA COLIECTION}

Adult smoking surveys

Data on adult smoking behaviour and cigarette brand preferences were obtained from two cross-sectional telephone surveys, one conducted from January to May 1988, and the second conducted between August 1993 and January 1994. Both surveys were conducted centrally by the same independent contractor using a modified, random-digit dialling technique with community-specific geographic screening to identify households within each COMMIT community. Both surveys involved a two stage selection: (a) an adult household member (aged 18 years or older) reported on the smoking status of all adults in that household, and (b) all smokers in the household who were aged 25-64 years were interviewed about their smoking behaviour, brand and type of cigarette smoked, and sociodemographic characteristics.

The 1988 adult survey identified representative samples of approximately 2800 households in each community. The mean response rate for the household rostering portion of the sur- vey was $83.2 \%$. Of the eligible smokers identified from the household rostering, $86.5 \%$ completed the extended interview. Overall, the 1988 prevalence survey gathered data on 99348 individuals, of whom 23644 were current smokers 18 years of age and older. Cigarette brand preference information is available only on current smokers aged 25-64 years who completed the extended interview.

The 1993 adult survey involved sampling approximately 2300 households per community. The mean response rate for the household $\frac{\bar{O}}{\bar{D}}$ rostering portion of the survey was $72.7 \%$. The response rate for the extended interview of $\varnothing$ smokers aged $25-64$ years of age was $80.8 \%$. ڤ Overall, the 1993 survey gathered data on $\overrightarrow{0}$ 79890 individuals, of whom 17375 were cur- $\vec{H}$ rent smokers 18 years of age and older; $\vec{\omega}$ cigarette brand preference data is available only $\vec{\partial}$ on current smokers aged 25 to 64 years.

\section{Adolescent smoking surveys}

Data on adolescent smoking behaviour and cigarette brand preferences were obtained fromes two school-based surveys of ninth-grade ${ }_{-}$ students, one conducted in autumn 1990, and음 the second conducted in autumn 1992. In bothyears, the sampling frame included ninth-gradec classrooms, from which a large enough random sample of classrooms was selected to yield approximately 400 students per community Both public and private schools with morethan 50 ninth-grade students were included in the sampling frame.

In both years, two to three weeks before then survey, a consent letter was sent to eacho student's home. The consent letter instructed parents to contact the school if they did no? wish to have their child participate in the survey. In addition, before administering the survey in each classroom, students were given the option not to participate. Students whळे chose not to complete the survey were asked tôֶ, sit at their desks and read or work quietly.

In 1990, an average of $99 \%$ (369/372) of elio gible classrooms participated (range: $84 \overline{\bar{O}}$ $100 \%$ ), yielding an average of 394 student suro veys per community (range $311-492$ ). In 1992 $97 \%(366 / 376)$ of eligible classroom participated (range 76-100\%) yielding an average of 404 student surveys per communit (range 266-486).

MEASUREMENT OF SMOKING BEHAVIOUR AND CIGARETTE BRAND USED

Adult smoking prevalence

Adult cigarette smoking prevalence was estimated as the percentage of adults (ages 18+) who were identified either by person interview or by proxy as a current smoke Current smokers were defined as persons whi reported having smoked at least 100 cigarette in their lifetime and who were smoking at the time of interview.

\section{Adult cigarette brand use}

Current smokers aged 25-64 years wh completed the extended interview were asked to provide the six-digit UPC code listed on the side of their current pack of cigarettes they 


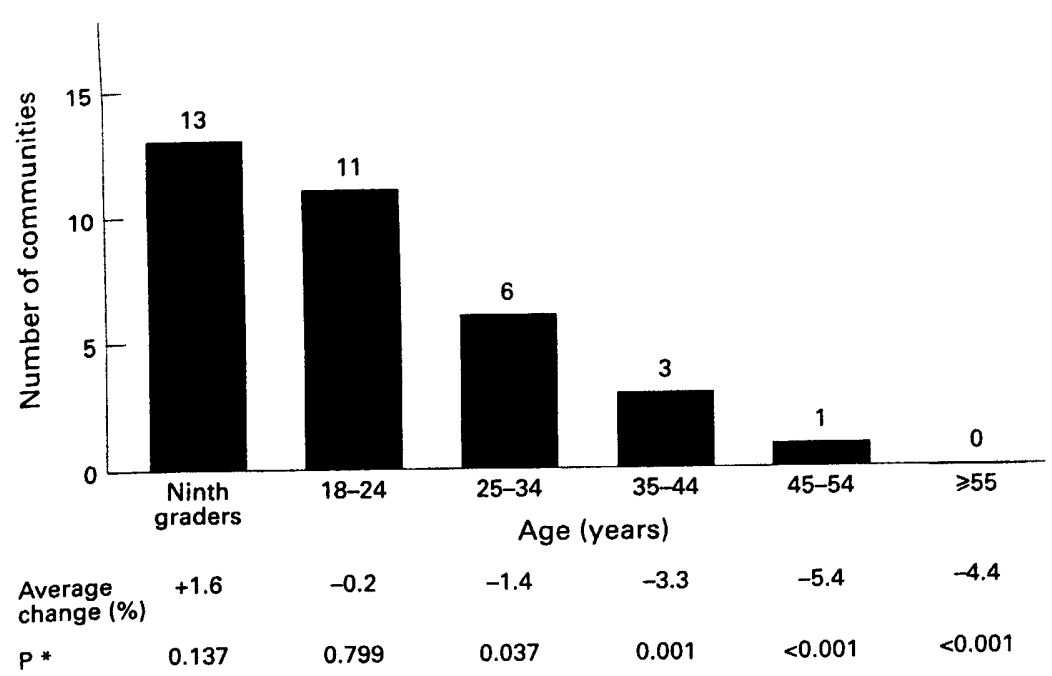

Figure 1 Number of the 18 study communities that saw an increase in smoking prevalence among ninth-graders (1990-1992) and adults (1988-1993) by age. prevalence among ninth-graders $(19 \mathrm{l})$ overall probability value equivalent to $P=0.05$ equals $P=0.004$ when Bonferroni adjustment for multiple comparisons is made.

were currently smoking. Each respondent's reported UPC code was linked to a specific cigarette brand. Respondents who did not have a pack available or who could not locate the UPC code on their cigarette pack were asked a series of questions to determine the brand of cigarettes they usually smoke now. Respondents were considered to be smoking generic or discount cigarettes if they self-reported smoking a generic brand of cigarettes or if the brand they smoked, identified from the UPC code or by self-report, could be classified as a discounted brand from the Maxwell consumer report. ${ }^{1920}$

\section{Adolescent smoking prevalence}

Adolescent cigarette smoking prevalence was estimated as the percentage of ninth-grade students who reported themselves to be current smokers. Current smokers were defined as those who reported having ever smoked a whole cigarette in their lifetime and who reported smoking cigarettes on one or more of the 30 days preceding the survey.

\section{Adolescent cigarette brand use}

Cigarette brand use was only measured in current smokers who reported that they usually buy their own cigarettes and was determined by responses to the question: "What brand do you usually buy?"

\section{ANALYSIS}

Estimates of adult and adolescent cigarette smoking prevalence and brand choice were computed separately by survey year and by community. Data from the adult crosssectional surveys were weighted to reflect variation in sampling fractions and response rates. In addition, the resulting smoking prevalence estimates, stratified by age, were standardised to community-specific age and sex distributions from the 1990 census. Because this census occurred approximately midway between the 1988 and 1993 surveys, it was chosen to standardise results from both surveys. This procedure is equivalent to a direct standardisation to the census distribution within each community.

The permutation test was used to evaluate differences in smoking prevalence rates for five different age groups of adults (18-24 years; 25-34 years; $35-44$ years; $45-54$ years; 55 years and older) between 1988 and 1993 and for ninth-grade students (aged 13-16 years) between 1990 and $1992 .^{21}$ To identify characteristics of smokers associated with use of different cigarette brands or brand categories (that is, discount/generic cigarettes) the $\chi^{2}$ test was used. These data are reported for only the most recent relevant survey year.

The results do not adjust for any effect of the COMMIT intervention. The permutation test was used to test for a COMMIT intervention effect for both adult (18+ years) and ninth-grade smoking prevalence changes for the eight complete pairs of communities (elimination of Hayward and New Rochelle deleted its matched community from the test). No effect was demonstrated at the $P<0.05$ level, hence all analyses were performed without regard to a communities designation as intervention or comparison status.

\section{Results}

TRENDS IN SMOKING PREVALENCE

Between 1988 and 1993, smoking prevalence rates among adults (18 years and older) declined $2.9 \%$. The overall decline in smoking prevalence was evident in 17 of the 18 communities; smoking prevalence remained unchanged in Greensboro, North Carolina (1988 $=25.4 \% ; 1993=25.5 \%)$. However, when stratified by age, the decline in smoking was not uniform for all age groups. As shown in figure 1, among 18-24 year olds, smoking prevalence did not change significantly when averaged across the 18 communities. Among adults aged over 25 years, a significant trend towards decreased smoking prevalence was evident. The opposite trend was seen among teenagers. As figure 1 shows, among ninth-grade students, smoking prevalence increased in 13 of the 18 communities between 1990 and 1992. In particular, smoking prevalence increased in the ninth grade among African Americans the most (data not shown).

CIGARETTE BRAND USE

Figure 2 shows the cigarette brand use of ninth-grade smokers in 1992, and adult smokers in 1993. Among adult smokers, cigarette brand use varied widely with 70 different brands reported. Across all communities, Marlboro was the only brand consistently reported by $20 \%$ or more of adult smokers; use of most brands was reported by fewer than $10 \%$ of smokers. Discount and generic cigarettes was reported by about $25 \%$ of adult smokers, although the percentage varied widely across communities (range 3-47\%).

In contrast to adults, ninth-grade smokers reported using fewer different cigarette brands (20 brands mentioned) and overwhelmingly restricted their brand use to either Marlboro, Camel, or Newport (average of the 18 communities $=91 \%$, range $78-100 \%$ ). Only a small 


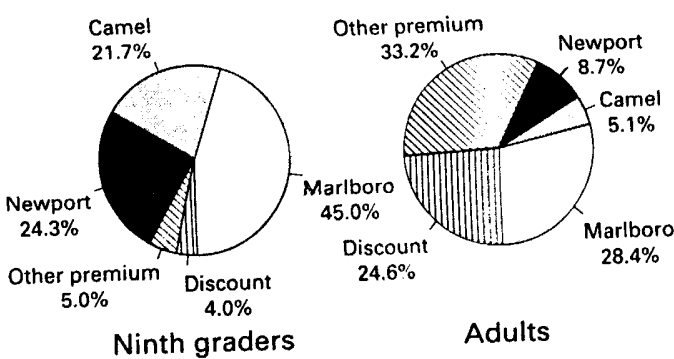

Figure 2 Brand choices among ninth-graders (1992) and adults (1993).

percentage of adolescent smokers reported usually buying discount or generic cigarettes (average of the 18 communities $=4 \%$, range 0-17\%).

Table 1 shows the characteristics of adult smokers in relationship to use of different cigarette brands and brand categories in 1993. Among adult smokers, use of Marlboro and Camel cigarettes was reported more frequently by men, whereas use of other premium brands and discount/generic cigarettes was reported more often by women. Black smokers were more likely to report using Newport and less likely to report using Marlboro, Camel, or discount/generic cigarettes than were white smokers. Users of discount/generic cigarettes were more likely than users of other brands of cigarettes to be heavier smokers. The brand of cigarette used was also related to age, with Marlboro, Camel and Newport more frequently used by those under age 35 , and other premium cigarette brands and discount generic cigarettes were more frequently used by those over age 35 .

Table 2 shows the characteristics of ninth-grade smokers in 1992 in relationship to gender, race, frequency, and amount of smoking. In contrast to adults, Marlboro was slightly more popular among female adolescent smokers than among males. Camel was more commonly purchased by males, whereas Newport was the overwhelming favourite of black dolescents. The relatively small number of adolescent smokers who reported usually

Table 1 Cigarette brand use among adult smokers (aged 25-64) in 1993 by age, gender, race, and amount smoked

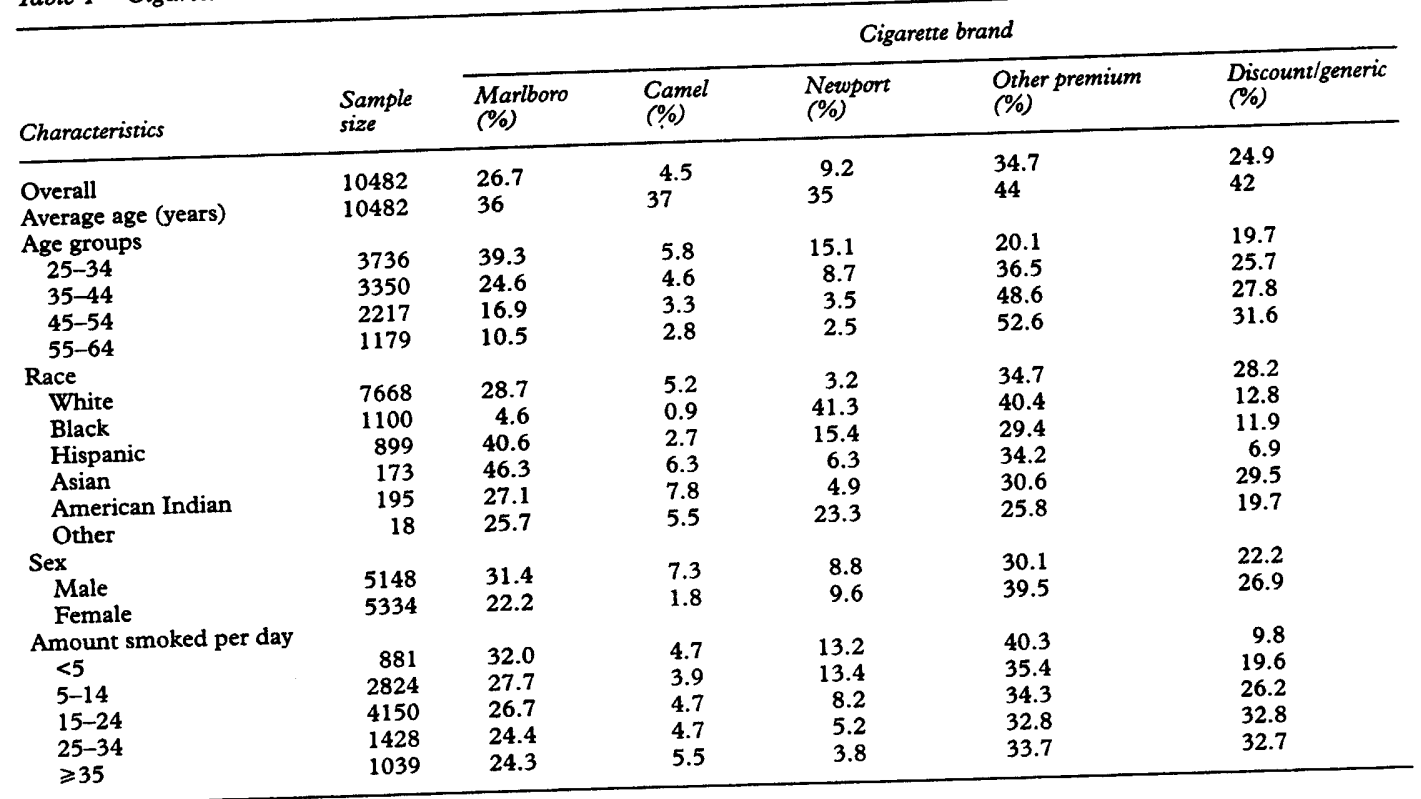

Table 2 Cigarette brand use among adolescent smokers in 1992 by gender, race, and amount smoked

\begin{tabular}{|c|c|c|c|c|c|c|}
\hline \multirow[b]{2}{*}{ Characteristics } & \multirow[b]{2}{*}{$\begin{array}{l}\text { Number reporting } \\
\text { usual brand }\end{array}$} & \multicolumn{5}{|c|}{ Cigarette brand usually purchased } \\
\hline & & $\begin{array}{l}\text { Marlboro } \\
(\%)\end{array}$ & $\begin{array}{l}\text { Camel } \\
(\%)\end{array}$ & $\begin{array}{l}\text { Newport } \\
(\%)\end{array}$ & $\begin{array}{l}\text { Other premium } \\
(\%)\end{array}$ & $\begin{array}{l}\text { Discount/generic } \\
\text { (\%) }\end{array}$ \\
\hline \multicolumn{7}{|l|}{ Overall } \\
\hline & $\begin{array}{l}383 \\
371\end{array}$ & $\begin{array}{l}42.3 \\
48.0\end{array}$ & $\begin{array}{l}26.6 \\
18.1\end{array}$ & $\begin{array}{l}21.1 \\
26.4\end{array}$ & $\begin{array}{l}6.3 \\
4.6\end{array}$ & $\begin{array}{l}3.7 \\
3.0\end{array}$ \\
\hline \multicolumn{6}{|l|}{$\begin{array}{l}\text { Female } \\
\text { Race } \\
\text { White }\end{array}$} & 3.5 \\
\hline Black & 60 & 5.0 & 10.0 & $\begin{array}{l}12.4 \\
75.0\end{array}$ & 6.7 & 3.3 \\
\hline Hispanic & 152 & 37.5 & 19.7 & 32.9 & 7.9 & 2.0 \\
\hline Asian & 25 & 20.0 & 12.0 & 56.0 & 4.0 & 8.0 \\
\hline American Indian & 23 & 56.5 & 26.1 & 8.7 & 0.0 & 8.7 \\
\hline \multirow{2}{*}{\multicolumn{7}{|c|}{$\begin{array}{l}\text { American Indian } \\
\text { Other } \\
\text { Days smoked of last } 30\end{array}$}} \\
\hline & 302 & 40.1 & 22.5 & 27.8 & 7.6 & 2.0 \\
\hline \multirow{2}{*}{\multicolumn{7}{|c|}{ Amount smoked per week }} \\
\hline & 74 & 48.6 & 20.3 & 20.3 & 9.5 & 1.4 \\
\hline $1-5$ & 182 & 45.1 & 19.2 & 29.1 & 4.9 & 1.6 \\
\hline $6-10$ & 59 & 49.2 & 16.9 & 23.7 & 3.4 & 6.8 \\
\hline $11-20$ & 123 & 37.4 & 27.6 & 24.4 & 6.5 & 4.1 \\
\hline$>20$ & 314 & 46.8 & 23.2 & 21.3 & 4.8 & 3.8 \\
\hline
\end{tabular}


Table 3 Cigarette brand use by adolescent smokers in 1990 and 1992 and by adult smokers (aged 25-64 years) in 1988 and 1993 in 18 communities in the United States

\begin{tabular}{|c|c|c|c|c|c|c|c|c|c|c|c|c|}
\hline \multirow[b]{3}{*}{ Community } & \multicolumn{6}{|c|}{ Adolescents (\%) } & \multicolumn{6}{|c|}{ Adults (\%) } \\
\hline & \multicolumn{2}{|c|}{$\begin{array}{l}\text { Marlboro, Camel, and } \\
\text { Newport }\end{array}$} & \multicolumn{2}{|c|}{ Other premium } & \multicolumn{2}{|c|}{ Discount/generic } & \multicolumn{2}{|c|}{$\begin{array}{l}\text { Marlboro, Camel, } \\
\text { and Newport }\end{array}$} & \multicolumn{2}{|c|}{ Other premium } & \multicolumn{2}{|c|}{ Discount/generic } \\
\hline & 1990 & 1992 & 1990 & 1992 & 1990 & 1992 & 1988 & 1993 & 1988 & 1993 & 1988 & 1993 \\
\hline $\begin{array}{l}\text { Vallejo, California } \\
\text { Cedar Rapids, }\end{array}$ & 90.9 & 90.0 & 9.1 & 6.7 & 0.0 & 3.3 & 31.9 & 40.8 & 62.8 & 40.0 & 5.3 & 19.2 \\
\hline $\begin{array}{l}\text { Cedar Rapids, } \\
\text { Iowa } \\
\text { Davenport, Iowa } \\
\text { Lowell, }\end{array}$ & 96.9 & 91.7 & 3.1 & 8.3 & 0.0 & 0.0 & 26.8 & 36.8 & 56.4 & 28.7 & 16.8 & 34.4 \\
\hline $\begin{array}{l}\text { Davenport, Iowa } \\
\text { Lowell, } \\
\text { Massachusetts }\end{array}$ & 96.4 & 90.0 & 1.8 & 7.5 & 1.8 & 2.5 & 27.3 & 36.7 & 62.8 & 32.1 & 9.9 & $\begin{array}{l}31.3 \\
118\end{array}$ \\
\hline $\begin{array}{l}\text { Lowell, } \\
\text { Massachusetts } \\
\text { Fitchburg, }\end{array}$ & 93.6 & 96.3 & 6.4 & 1.9 & 0.0 & 1.9 & 35.8 & 47.7 & 61.1 & 30.5 & 3.0 & \\
\hline $\begin{array}{l}\text { Fitchburg, } \\
\text { Massachusetts }\end{array}$ & 97.3 & 88.4 & 2.7 & 2.3 & 0.0 & 9.3 & 35.4 & 39.0 & 60.3 & 32.8 & 4.2 & 28.2 \\
\hline $\begin{array}{l}\text { Paterson, New } \\
\text { Jersey }\end{array}$ & 96.8 & 92.1 & 3.2 & 7.9 & 0.0 & 0.0 & 41.2 & 59.2 & 56.7 & 37.6 & 2.1 & 3.1 \\
\hline $\begin{array}{l}\text { Trenton, New } \\
\text { Jersey }\end{array}$ & 95.2 & 100.0 & 4.8 & 0.0 & 0.0 & 0.0 & 37.3 & 53.2 & 60.7 & 39.6 & 2.1 & 7.2 \\
\hline $\begin{array}{l}\text { Las Cruces, New } \\
\text { Mexico }\end{array}$ & 96.5 & 80.6 & 2.4 & 11.9 & 1.2 & 7.5 & 35.6 & 45.8 & 57.2 & 31.9 & 7.2 & 22.3 \\
\hline $\begin{array}{l}\text { Santa Fe, New } \\
\text { Mexico }\end{array}$ & 93.1 & 95.9 & 5.6 & 4.1 & 1.4 & 0.0 & 40.1 & 46.3 & 56.1 & 35.4 & 3.8 & 18.3 \\
\hline $\begin{array}{l}\text { Yonkers, New } \\
\text { York }\end{array}$ & 84.3 & 89.4 & 15.7 & 10.6 & 0.0 & 0.0 & 35.1 & 53.8 & 63.6 & 39.0 & 1.2 & 7.2 \\
\hline Utica, New York & 91.9 & 100.0 & 7.1 & 0.0 & 0.0 & 0.0 & 30.5 & 41.1 & 60.0 & 32.3 & 9.5 & 26.6 \\
\hline $\begin{array}{l}\text { Binghamton, New } \\
\text { York }\end{array}$ & 96.2 & 94.4 & 3.8 & 5.6 & 0.0 & 0.0 & 31.6 & 41.3 & 63.4 & 30.3 & 5.1 & 28.4 \\
\hline $\begin{array}{l}\text { Greensboro, } \\
\text { North Carolina }\end{array}$ & 82.5 & 93.9 & 14.0 & 6.1 & 3.5 & 0.0 & 25.5 & 34.8 & 67.4 & 42.7 & 7.1 & 22.5 \\
\hline $\begin{array}{l}\text { Raleigh, North } \\
\text { Carolina }\end{array}$ & 85.4 & 88.4 & 14.6 & 9.3 & 0.0 & 2.3 & 23.7 & 32.9 & 72.4 & 45.2 & 3.9 & 21.9 \\
\hline Medford, Oregon & 100.0 & 83.9 & 0.0 & 0.0 & 0.0 & 16.1 & 39.6 & 35.8 & 51.9 & 22.8 & 8.6 & 41.4 \\
\hline Albany, Oregon & 100.0 & $\begin{array}{l}77.8 \\
927\end{array}$ & 0.0 & 5.6 & 0.0 & 16.7 & 35.8 & 37.9 & $\begin{array}{l}53.5 \\
56.9\end{array}$ & $\begin{array}{l}28.2 \\
33.0\end{array}$ & $\begin{array}{r}10.7 \\
5.3\end{array}$ & $\begin{array}{l}33.9 \\
26.3\end{array}$ \\
\hline $\begin{array}{l}\text { Bellingham, } \\
\text { Washington }\end{array}$ & 91.9 & 92.7 & 6.5 & 2.4 & 1.6 & 4.9 & 37.8 & 40.6 & 56.9 & 33.0 & & 20.3 \\
\hline $\begin{array}{l}\text { Longview, } \\
\text { Washington }\end{array}$ & 95.5 & 93.3 & 0.0 & 0.0 & 4.5 & 6.7 & 39.3 & 32.2 & 47.8 & 21.0 & 12.9 & 46.8 \\
\hline Totals & 93.6 & 91.0 & 5.6 & 5.0 & 0.8 & 4.0 & 33.9 & 42.0 & 59.5 & 33.5 & 6.6 & 24.5 \\
\hline
\end{tabular}

buying discount/generic cigarettes, on average reported smoking more frequently and more cigarettes per day than adolescents using premium brand cigarettes (data not shown).

CHANGE IN CIGARETTE BRAND USE

To describe differences in cigarette brand use by adolescent and adult smokers over time, cigarette brands were grouped into the following three categories.

- Brands popular among adolescent smokers: Marlboro, Camel and Newport

- All other premium brands

- Discount/generic brands.

Table 3 shows the percentage of adolescent smokers in 1990 and 1992 and adult smokers in 1988 and 1993 distributed in each of three brand categories. The data in this table show that among adolescent smokers there was little change in the cigarette brand category between 1990 and 1992. Marlboro, Camel, and Newport were the overwhelming brand choice of adolescent smokers in all 18 communities in both years. Unlike adolescents, between 1988 and 1993, there was a marked increase among adults in the use of discount/generic cigarettes as well as Marlboro, Camel, and Newport, and a decline in the use of other premium brands.

\section{Discussion}

There are three main findings from this study.

- Cigarette brand use was found to be much more tightly concentrated in adolescent smokers compared with their adult counterparts in the same communities, with young smokers most likely to use the most heavily marketed cigarette brands-Marlboro, Newport, and Camel

- The cigarette brand use of adolescent smokers appeared to be more stable than among adult smokers, who have switched in large numbers to discount and generic cigarettes

- Smoking prevalence rates appear to be increasing in teenagers while declining among those 25 years of age and older.

The trend toward increased smoking by adolescents was evident in 13 of the 18 communities studied and was apparent in all race/ethnic groups. Young African Americans had the lowest overall rate of smoking, but demonstrated the largest increase in smoking prevalence of all race/ethnic groups, suggesting that the decade-long decline of smoking among young black people may be reversing. ${ }^{62-24}$

The findings from this study are unique in that they reflect a pattern of results observed across 18 separate and diverse communities. Unlike findings from a single community study or the results derived from a single national survey, the opportunity to look for consistency in results across many different communities over time lends weight to the validity of the observations made from these data. However, like all studies, there are some limitations which the reader should keep in mind when interpreting these results.

Direct comparisons between adolescents and adults must be made cautiously for several reasons. First, the questions used to measure smoking behaviour and cigarette brand use differed for teenagers and adults. With regard to brand use, adults were asked to report their 
current cigarette brand, while teenagers were asked to report their usual brand purchased. However, a recent study by DiFranza et al found essentially the same frequency distribution of cigarette brands reported by smokers using different questions to measure brand use. $^{25}$

Second, the timing of surveys differed for adolescents and adults. Adults were survered in 1988 and 1993, whereas adolescents were surveyed in 1990 and 1992. The shorter time span for the surveys of young people might be expected to yield less opportunity fir observing change. Yet, smoking prevalence changed more among teenagers over only a two-year period compared with young adults (aged 18-24 years) observed over a five-year period. The information on brand use obtained from adults in 1993 may not be directly comparable to the data on brand use by adolescents collected in 1992, because of price reductions on premium cigarettes introduced in spring 1993. In April, 1993 Philip Morris announced a $20 \%$ reduction in the price of Marlboro and other premiumbrand cigarettes, a move quickly followed by other premium brands. ${ }^{26}$ This price reduction is credited with helping Marlboro increase its sales and market share in the last quarter of $1993{ }^{19}$ Between 1988 and 1993, we observed an increase in the percentage of adult smokers using Marlboro, Newport, and Camel cigarettes. It seems logical to speculate that at least a share of the increase in the use of these premium brands among adults smokers surveyed in autumn 1993 was the result of the price reductions in these brands introduced in spring 1993. The effect of price on brand choice by adult smokers is consistent with our observation of the increased popularity of discount and generic cigarettes among adult smokers. ${ }^{2027}$

Finally, the method used for data collection differed for adults and teenagers. Data on teenage smoking behaviour was collected using school-based, self-administered surveys, whereas the data on adult smoking was collected from centrally conducted telephone surveys, with proxy information used in computation of smoking rates. Several studies have demonstrated that the method used for data collection can influence responses to questions about tobacco use and other topics. $^{22} 2829$ In general, evidence suggests that teenagers, especially younger teenagers, are more likely to accurately report their smoking behaviour using an anonymous, selfadministered survey methodology compared with either a personal household or telephone survey. ${ }^{22}$ For adults, reports of smoking behaviour do not seem to be quite as sensitive to the data collection method used. ${ }^{30} 31$ Moreover, as we used the same data collection method at different times for teenagers and adults, estimates of changes in smoking behaviour should not be influenced by the data collection method.

Although this study does not prove cigarette advertising encourages young people to smoke, our results are consistent with the hypothesis hat cigarette advertising affects the brand preferences of the young more than adults. The increased rate of smoking by adolescents occurred during a period when real expenditures for total cigarette advertising and promotion increased. ${ }^{32}$ Moreover, within the same communities at about the same time, smoking rates among adults, were declining. The observation that, within the same communities, young people smoke the most heavily advertised cigarette brands, and smoke many fewer brands than adults, lends further evidence to support the idea that cigarette marketing has a greater impact on the young than on adults. Further, the disparity in brand choices between teenagers and adults in the same communities suggests that the impact of advertising on brand choices among young people cannot simply be attributed to teenagers imitating adult brand choices. Among adult smokers, we found a marked Ane percentage using discount and generic cigarettes that rely less on advertising and use little or no imagery on their packaging.

Cigarette companies have a strong economic incentive to direct at least a share of their advertising resources toward the recruitment of new smokers. ${ }^{4}{ }^{10}$ Because smokers are highly brand loyal, capturing a healthy share of the starter market helps guarantee a brand's success and long-term profits.

The results of this study add to an expanding body of research evidence that points to the conclusion that, whether intended or not, cigarette marketing has a significant effect on cigarette marketing in young people. ${ }^{2-6} \quad 11-132233-39$ The conclusion that cigarette marketing influences the smoking behaviour of young people has important public policy implications. First, it suggests that regulating cigarette marketing practices can be expected to be an effective policy intervention to discourage exing adolescents. Second the finding that young people are influenced by cigarette marketing suggests that comparable counter-advertising campaigns, designed to counteract the imagery presented in cigarette advertisements, could potentially be an effective means to discourage young people from smoking. Finally, the fact that it is already illegal to sell cigarettes to minors, suggests that the government has a legitimate interest in regulating efforts to promote the sale of cigarettes to adolescents.

Support for this research has been provided by the National Suppert Wood Johnson Foundation. We Cancer Institute and to are indebted to our collerdinating center, Information Managesites, the COMMI coordinat at the National Cancer Institute $\mathbb{C}$ ment Services, Inc., and staff at the massive data collection who planned and coordin study.

Rafferty I. Advertising and smoking: a smouldering debate. $B r f$ Addict 1989;84:1241-6.

the teen epidemic. Consumer $\stackrel{D}{D}$ Anon. Hooked on tobacc:

Reports 1995 Mar:142-7. Paulman PM, et al. RIR Nabis- $Q$

3 DiFranza JR, Richards JW, Paulman PM, et al. RJR Nabisco's cartoon camel promo

4 Pollay RW, Levack $A$. The targeting of youth by cigarette $O$ marketers: archival evidence on trial. In: McAlster Rothschilds ML, eds. Advances in Consumer Research 1989;20:266-71. Provo, Utah: Association of Consumero Research. 

5 Warner K. Selling smoking: cigaretti udvertising and public tion, 1986 .

6 Lynch BS, Bonnie RJ, eds. Growing is whacco free: preventing nicotine addiction in children and wuths. Washington, National Academy Press, Institute of Medicine, 1994. 16

7 Boddewyn JJ. Furerile smoking initiation and advertising: a 16 country study of the perceived role of d.tertising and other factors bearing on juvenile smoking initition. New International Advertising Association, 1989. Dubow JS. A Camel wronged. Food ind Beverage Marketing 1992 Feb: 13

1992 Feb:13. Siegel M, Nelson DE, Peddicord switihing: results from the cigarette brand and company switihing: results from the Adult 16.

10 Cummings KM, Hyland A, Lewit E. Shopland D. Discrepancies in cigarette brand sales and adult market share: are new teen smokers filling the sap? Tobacco Contro 1997;6(suppl 2):S38-43.

11 US Centers for Disease Control. Comparison of the cigarette brand preferences of adult and teenaged smokers-United States, 1992;41:169-73, 179-81.

12 US Centers for Disease Control. Changes in cigarette brand preferences of adolescent smoker

13 Pollay RW, Siddarth S, Siegel M, et $d$. The last straw? Cigarette advertising and realized market shares among youths and

14 COMMIT Research Group. Community Intervention Trial for Smoking Cessation (COMMIT): summary of desig and intervention. 7 Natl Cancer Inst 1991;83:1620-8.

15 Mattson ME, Cummings KM, Lynn WR, et al. Evaluation plan for the community intervention trial for smoking cessation (COMMIT). Int $Q$ Commin Health Educ 1991, 11:271-90.

16 COMMIT Research Group. Community Intervention Trial for Smoking Cessation (COMMIT). I. Cohort results from a four-year comm

17 COMMIT Research Group. Community Intervention Trial for Smoking Cessation (COMMIT). II. Changes in adult cigarette smoking prevalence. Am f Public Health 1995; 85:193-200.

18 Orlandi M, Bowen D, Lichtenstein E, Cummings KM, Corle D. Effects of community-based smoking control interventions on adolescent smoking: results of the

9 Maxwell JC Jr. The Maxwell consumer report. Fourth-quarter and year-end 1993 sales estimates for the cigarette industry. and year-end 1993 sales estimates for the cigarette industry. Richmond, VA: Wheat First Securities, 10 February 1994.
Cum Cummings KM, Hyland A, Lewit E, Shopland D. Use of discount cigarettes by smokers in 20 communities in the United States, 1988-1993. Tobacto Control 1997;6(suppl
2):S25-30. 21 Edington ES. Randomization tests, 2nd ed. New York, NY.

22 US Department of Health and Human Services. Preventing tobacco use among young people. A report of the Surgeon General, 1994. Atlanta, Georgia: Public Health Service, Centers for Disease Control and Prevention, Office on Smoking and Health, 1994 (US S N 017-001-00491-0.)
23 Giovino GA, Henninfeld JE, Tomer SL, et al. Epidemiology of tobacc

$$
17: 48-65
$$

24 Johnston LD, O'Malley PM, Bachman JG. National survey results on drug use from the monitoring the future study, 19751993. Volume 1: secondary school students. Rockville, 1993. Volume US Department of Health and Human Maryland: US Department of Neational Institutes of Services, Public Institute on Drug Abuse, 1994.

25 DiFan J Eddy JJ, Brown LF, et al. Tobacco acquisition DiFranza JR, Eddy Jj, Browi Lenth. Tobacco Control and cigarette b.

26 Shapiro E. Cigarette burn: Philip Morris price cut on Marlboro jolts industry and upsets rosey profit assumptions. boro jolts industry and upset fournal 1995 Apr 5:A1, A10.

27 Cavin SW, Pierce JP. Low cost cigarettes and smoking behavior in California, 1990-1993. Am f Prev Med 1996; 12:17-21.

28 There $\mathrm{NW}$. Effects of mode of in administradon and $\mathrm{TT}$ Gfroerer IC eds. Survey measure Turner CF, Lessler $J$, Groer Judies. US Department of ment of drug use: methodological sulic Health Service, AlcoHealth and Human Servis hol, Drug Abuse, and Mental Health Administration. Rockville, Maryla

Pirie PL Pirie PL, Murray DM, Luepker RV. Smoking prevalence in, a cohort of adolescents, including absentees,

30 Gilpin EA, Pierce Jp, Levin SW. Estimates of population smoking prevalence self versus proxy reports of smoking smoking prevalence Health 1994;84:1576-9.

31 US D. Artm the health consequences of smoking: 25 years of progress. $A$
report of the Surgeon General, 1989. Rockville, Maryland: Public Health Service, Centers for Disease Control, Office on Smoking and Health, 1989. (DHHS Publication No on Smoking and

32 US Federal Trade Commission. Federal trade commission report to congress for 1993 pursuent to the federal cigarette labeling and adverting Commission, 1995 .

33 Hastings GB, Ryan H, Teer P, Mackintosh Am. Cigarette advertising and children's smoking: why Reg was withdrawn. BMf 1994;309:933-7.

34 Aitkens PP, Eadie DR, Hastings GB, Haywood AJ. Predisposing effects of cigarette advertising on children's 90.

35 Botvin GJ, Goldberg CJ, Botvin EM, Dusenburg L. Smoking behavior of adolescents exposed to cigaret

ing. Public Health Reports 1993;108:217-24. Pierce JP, Lee L, Gilpin EA. Smoking initiation by adolescents girls, 1944 through 1988, an associat

targeted advertising. $f A M A$ ical analysis of tobacco marketPierce JP, Gilpin E. A historical analysis of the United States: ing and uptake of smoking by youth in the

38 US Centers for Disease Control. Trends in smoking initiation among adolescents and young adults-United initiation among adolescents and 44:521-4.

39 Evans N, Farkas A, Gilpin E, et al. Influence of tobacco marketing and exposure to smokers on adolescent suscep 